Original Paper

\title{
Pelatihan yang Dibarengi dengan Demontrasi Teknik Budidaya Eucheuma cottonii dan Eucheuma striatum dengan Sistim Rakit Apung untuk Meningkatkan Kualitas Hasil Rumput Laut di Teluk Ekas Lombok Timur
}

\author{
Sunarpi ${ }^{1 *}$, Eka S. Prasedya1 ${ }^{1}$ Ahmad Jupri ${ }^{1}$, Anggit L. Sunarwidhi ${ }^{2}$, Bq T. Khairina \\ Ilhami $^{1}$, Sri Widyastuti ${ }^{3}$ \\ 1Pusat Unggulan Biosains dan Bioteknologi FMIPA Universitas Mataram, Lombok, Nusa Tenggara \\ Barat, Indonesia \\ ${ }^{2}$ Program Studi Farmasi, Fakultas Kedokteran Universitas Mataram, Lombok, Nusa Tenggara Barat, \\ Indonesia \\ ${ }^{3}$ Fakultas Teknologi Pangan dan Agroindustri Universitas Mataram, Lombok, Nusa Tenggara Barat, \\ Indonesia.
}

DOI: $\underline{10.29303 / \text { jpmpi.v3i1.448 }}$

Sitasi: Sunarpi, S., Prasedya, E., Jupri, A., Sunarwidhi, A., Ilhami, B., \& Widyastuti, S. (2020). Pelatihan yang Dibarengi dengan Demontrasi Teknik Budidaya Eucheuma cottonii dan Eucheuma striatum dengan Sistim Rakit Apung untuk Meningkatkan Kualitas Hasil Rumput Laut di Teluk Ekas Lombok Timur. Jurnal Pengabdian Magister Pendidikan IPA, 3(1). doi:https://doi.org/10.29303/jpmpi.v3i1.448

*Corresponding Author: Sunarpi; Pusat Unggulan Biosains dan Bioteknologi FMIPA Universitas Mataram, Lombok, Nusa Tenggara Barat, Indonesia.

Email: ekajp@yahoo.com

\begin{abstract}
Abstrak: Rumput laut yang secara ilmiah dikenal dengan nama makroalga, merupakan komoditi ekspor bernilai ekonomi tinggi, karena mengandung senyawa hidrokoloid seperti karaginan, agar dan alginat, yang merupakan bahan baku industri pangan dan farmasi. Karena itu, mutu rumput laut ditentukan oleh kualitas senyawa hidrokoloid yang dihasilkan. Mutu Eucheuma cottonii NTB rendah karena kadar karaginan dan kekerasan gel yang rendah, disamping kadar kotoran di atas $2 \%$. Artikel ini melaporkan penyuluhan dibarengi dengan demonstrasi teknik budidaya Eucheuma cottonii dan Eucheuma striatum kepada pembudidaya rumput laut di Teluk Ekas bertujuan untuk meningkatkan mutu rumput laut $E$. cottonii dan $E$. striatum untuk dapat memenuhi standar mutu ekspor. Pengabdian dilakukan dalam bentuk penyuluhan dan demontransi teknik budidaya dengan metode rakit selama satu musim tanam (45 hari), awal mei-pertengahan juni tahun 2020. Selama periode tersebut, didemonstrasikan laju pertumbuhan, berat rendemen dan kadar kotoran rumput laut yang dihasilkan. Penyuluhan yang dibarengi dengan praktek langsung tersebut dapat dicontoh oleh pembudidaya rumput laut pada musim tanam berikutnya untuk dapat mencapai standar mutu ekspor rumput Eucheuma yang dihasilkan. Dengan demikian, penyuluhan ini dapat mendorong peningkatan harga jual rumput kering pada tingkat pembudidaya dari sekitar 14.000 rupiah per kilogram berat kering menjadi 22.000 rupiah per kilogram berat kering.
\end{abstract}

Kata Kunci: Teknik budidaya; rumput laut; rendemen; Teluk Ekas. 


\section{Pendahuluan}

Makroalga, yang sehari-hari dikenal dengan nama rumput laut, merupakan salah satu komoditi laut yang memiliki nikai ekonomi tinggi. Hal ini disebabkan karena rumput laut mengandung senyawa hidrokoloid, seperti karaginan, agar dan alginat, yang merupakan bahan baku industri pangan, farmasi dan pertanian (Herawati, 2018). Karena itu, mutu rumput laut yang dihasilkan sangat ditentukan kualitas senyawa hidrokoloid yang dihasilkan oleh rumput laut tersebut, yang pada akhirnya menentukan harga per kilogram rumput laut kering, baik pada tingkat petani atau pada tingkat pengepul.

Rumput laut memiliki pasar pada setiap level umur panennya. Sebagai contoh, pada umur dua minggu memiliki pasar, pembudidaya yang membutuhkan bibit, sehingga pembudidaya bisa menjualnya dengan harga murah sebagai bibit. Pada level umur berikutnya (30 hari) rumput laut juga memiliki pasar, untuk digunakan sebagai bahan baku pangan untuk dijadikan permen, dodol dan aneka pangan lainnya (Alamsyah $e t$ $a l ., 2013)$. Penjualan pada level seperti ini tentu harganya sangatlah murah sekitar 12.000 rupiah per kilogram kering yang terkadang juga dibawah 10.000 rupiah per kilogram kering.

Selain persoalan harga jual rumput laut, penimbunan karaginan belum mencapai puncaknya, yang tentu akan berdampak terhadap kadar karaginan. Selain rendahnya kadar karaginan, kekerasan gel karaginan yang dihasilkan oleh rumput laut yang dipanen pada umur 30 hari juga rendah. Mengingat rendahnya kadar dan kekerasan gel karaginan yang dihasilkan oleh rumput laut yang dipanen pada umur 30 hari, menjadi salah satu faktor penting yang menyebabkan tidak tercapainya mutu dan standar ekspor rumput laut Nusa Tenggara Barat.

Berdasarkan fakta di atas, lama panen mempengaruhi mutu rumput laut. Hasil studi sebelumnya menunjukkan bahwa laju penimbunan karaginan menurun pada umur 45 hari (Sunarpi et al., 2005) dan berhenti penimbunan secara total pada umur 60 hari (Ortado, 2005). Atas dasar fakta teoritis itulah, maka praktek budidaya rumput laut di Filipina, panen dilakukan pada umur 60 hari. Berdasarkan kenyataan itulah, maka kualitas karaginan yang dihasilkan oleh rumput laut Filipina sangatlah tinggi.

Selain mempengaruhi kadar dan kualitas karaginan, lama panen juga mempengaruhi rendemen rumput laut yang dihasilkan. Bila rumput laut dipanen pada umur $<30$ hari, rendemen yang dihasilkan berkisar $15-20 \%$. Bila dipanen pada umur sekitar 45 hari, rendemen yang dihasilkan oleh rumput laut sekitar $30 \%$, dan tentu rendemen yang dihasilkan oleh rumput laut terus meningkat sejalan dengan meningkatnya umur panen, sekitar 40\% pada umur 60 hari (Ortado, 2005). Dalam kenyataannya umur panen rumput laut NTB sebagian besar pada umur 30 hari. Hal inilah yang menyebabkan rumput laut NTB tidak dapat memenuhi standar ekspor.

Selain rendemen, kadar dan kekerasan gel, kadar kotoran juga merupakan faktor penting penentu mutu ekspor rumput laut (Ega et al., 2016). Fakta yang ada saat ini, kadar kotoran rumput laut NTB $>2 \%$. Kadar kotoran itu ditentukan oleh cara penanganan pasca panen rumput laut.

Selain rendemen, kadar dan kekerasan gel karaginan yang rendah, kadar kotoran rumput laut NTB $>2 \%$, sekitar $4-5 \%$. Di sisi lain, standar mutu ekspor rumput laut mensyaratkan kadar kotoran maksimum $2 \%$. Hal ini disebabkan karena praktek pasca panen yang penjemurannya langsung di pasir laut, tidak beralaskan para-para atau beralaskan plastik. Rumput laut yang mengandung kotoran $>2 \%$ memiliki harga jual 12.000-13.000 rupiah per kilogram, padahal jika kadar kotoran rumput laut maksimum $2 \%$, maka harga jual rumput laut lebih tinggi, sekitar 20.000-22.000 rupiah per kilogram rumput laut kering.

Berdasarkan kenyataan itulah, maka artikel ini melaporkan penyuluhan yang 
dirangkaikan dengan demonstrasi teknologi budidaya rumput laut E. cottonii dan E. striatum dengan sistim rakit apung kepada pembudidaya rumput laut di Teluk Ekas Lombok Timur dalam rangka untuk meningkatkan mutu hasil, harga jual rumput laut, yang pada akhirnya dapat meningkatan pembudidaya rumput laut di Teluk Ekas Lombok Timur. Kegiatan tersebut telah dilakukan selama dua bulan sejak pertengah April sampai dengan pertengah Juni tahun 2020.

\section{Metode Pelaksanaan}

Metode pelaksanaan penyuluhan yang dirangkaikan dengan demonstrasi teknologi budidaya rumput laut dilakukan selama dua bulan, terhitung mulai tanggal 15 April sampai dengan 15 Juni 2020. Tahapan kegiatan adalah sebagai berikut:

1) Persiapan kelompok pembudidaya

Ada 2 kelompok pembudidaya yang menjadi sasaran penyuluhan dan demonstrasi teknologi budidaya masing-masing kelompok terdiri atas 5 orang, sehingga total sasaran penyuluhan dan demonstrasi menjadi 10 orang.

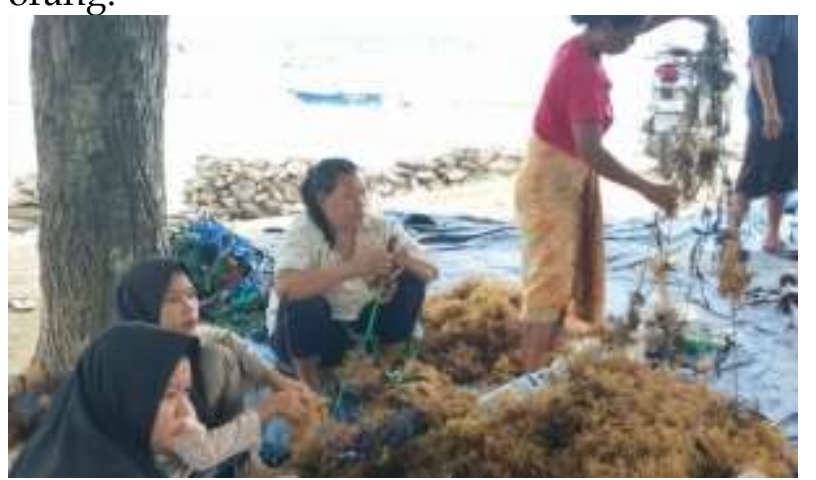

Gambar 1. Kelompok pembudidaya sedang mengikat bibit rumput laut

Kelompok pembudidaya diberikan penjelasan tentang teknologi budidaya dan penanganan pasca panen rumput laut untuk dapat mencapai standar ekspor, sehingga nilai jual rumput laut kering dapat ditingkatkan.
2) Pembagian rakit, bibit, dan persiapan penanaman

Setiap kelompok terdiri atas lima orang, sehingga ada 10 orang pembudidaya rumput laut yang terlibat pada kegiatan tersebut. Setiap orang mendapatkan 5 rakit dan $50 \mathrm{~kg}$ bibit rumput laut (30 kg E. cottonii dan $20 \mathrm{~kg}$ E. striatum). Setiap rakit terdiri atas 100 titik tanam, dan setiap titik tanam terdiri atas 100 gram bibit. Dengan demikian, setiap rakit mengandung $10 \mathrm{~kg}$ bibit rumput laut. Selanjutnya, rakit yang mengandung bibit tersebut diletakkan di perairan Teluk Ekas pada tanggal 15 april 2020, dan dibiarkan tumbuh selama 45 hari sampai dengan tanggal 30 Mei 2020.

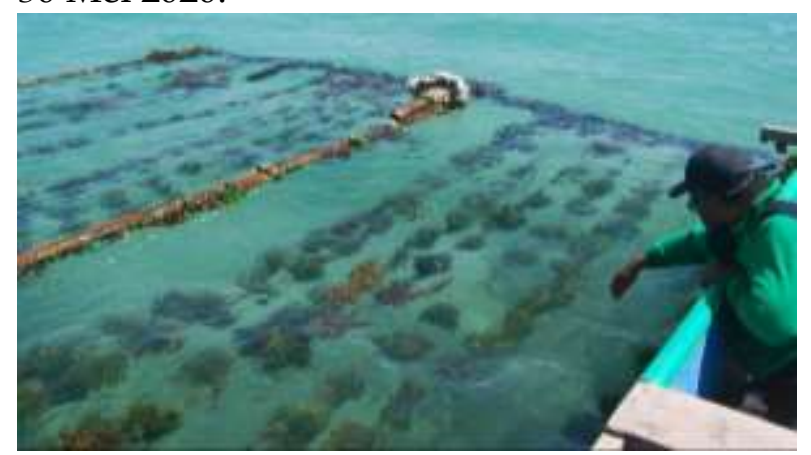

Gambar 2. Pertumbuhan E. cottonii dan E. striatum pada rakit apung

3) Panen rumput laut

Rumput laut, baik E. cottonii, ataupun $E$. striatum pada rakit dipanen umur 45 hari.

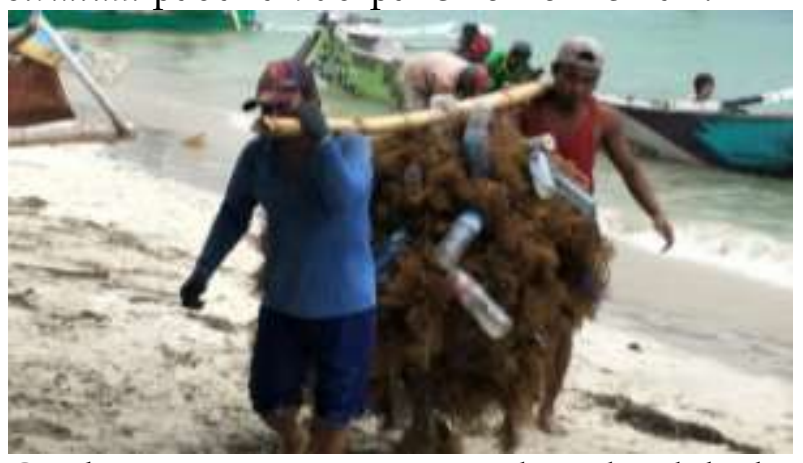

Gambar 3. Proses panen rumput laut di Teluk Ekas

4) Penanganan pasca panen rumput laut

Setelah rumput laut dipanen pada umur

45 hari dijemur pada lantai jemur yang sudah dibersihkan dari pasir. Penjemuran rumput laut E. cottonii dan E. striatum dilakukan selama dua hari . 


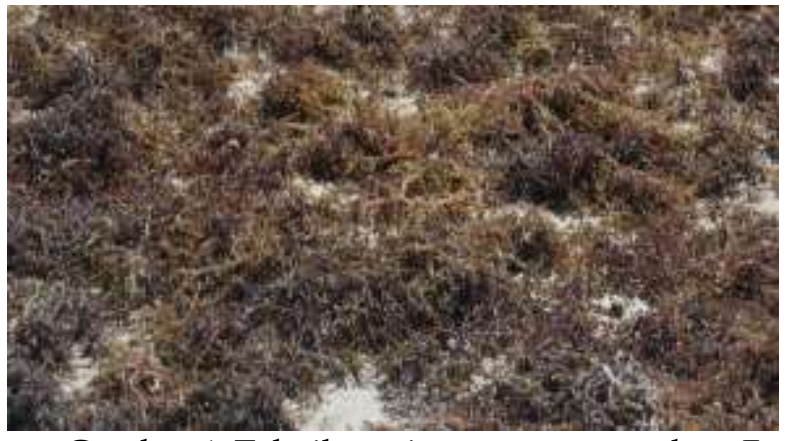

Gambar 4. Teknik penjemuran rumput laut $E$. cottonii pasca panen

\section{Hasil dan Pembahasan}

Pelatihan dan demonstrasi yang telah dilakukan terhadap pembudidaya rumput laut sangat berpengaruh terhadap perbedaan berat basah. Perbandingan hasil rumput laut sebelum dan setelah pelatihan ditunjukkan pada Tabel 3.

Tabel 3. Pengaruh pelatihan dan demonstrasi terhadap berat basah rumput laut

\begin{tabular}{llccc}
\hline No & Jenis Rumput Laut & \multicolumn{2}{c}{ Berat Basah per Rakit $(\mathrm{kg})$} & \multirow{2}{*}{$\begin{array}{c}\text { Peningkatan } \\
(\%)\end{array}$} \\
\cline { 3 - 4 } & & Sebelum pelatihan & Setelah pelatihan & \\
\hline 1. & E. cottonii & 500 & 750 & 50 \\
& E.striatum & 570 & 800 & 40.35 \\
\hline
\end{tabular}

Berdasarkan Tabel 3, terjadi peningkatan sebesar $50 \%$ untuk jenis rumput laut E. cottonii dan $40.35 \%$ E. striatum. Peningkatan berat basah rumput laut dipengaruhi oleh faktor fisika-kimia perairan, tingginya penyerapan unsur hara, umur panen dan penanganan pasca panen yang tepat.

Tinggi atau rendahnya rendemen rumput laut dipengaruhi oleh umur panen. Sebelum melakukan pelatihan, pembudidaya rumput laut memanen pada saat rumput laut berumur 30 hari. Setelah pelatihan, umur panen rumput laut yaitu 45 hari. Apabila pemanenan dilakukan lebih awal mengakibatkan rendahnya kandungan karaginan dan kadar air yang tinggi sehingga mutu rumput laut yang dihasilkan rendah. Umur panen yang tepat dapat meningkatkan rendemen rumput laut baik jenis E. cottonii maupun E. striatum (Tabel 4).

Tabel 4. Pengaruh pelatihan dan demonstrasi terhadap berat kering dan rendemen

\begin{tabular}{|c|c|c|c|c|c|c|}
\hline \multirow[b]{2}{*}{ No. } & \multirow[b]{2}{*}{ Jenis Rumput Laut } & \multicolumn{2}{|c|}{ Berat Kering (kg) } & \multirow[b]{2}{*}{$\begin{array}{c}\text { Peningkatan } \\
(\%)\end{array}$} & \multicolumn{2}{|c|}{ Rendemen $(100 \%)$} \\
\hline & & $\begin{array}{l}\text { Sebelum } \\
\text { Pelatihan }\end{array}$ & $\begin{array}{l}\text { Setelah } \\
\text { Pelatihan }\end{array}$ & & Sebelum & Sesudah \\
\hline 1. & E. cottonii & 60 & 180 & 200 & 12 & 24 \\
\hline 2. & E. striatum & 90 & 200 & 122,22 & 15.78 & 25 \\
\hline
\end{tabular}

Tabel 5. Pengaruh pelatihan dan demonstrasi terhadap kadar kotoran

\begin{tabular}{llccc}
\hline \multirow{2}{*}{ No. } & \multirow{2}{*}{ Jenis Rumput Laut } & \multicolumn{2}{c}{ Kadar Kotoran } & \multirow{2}{c}{$\begin{array}{c}\text { Peningkatan } \\
(\%)\end{array}$} \\
\cline { 3 - 4 } & & Sebelum Pelatihan & Setelah Pelatihan & \\
\hline 1. & E. cottonii & 4 & 2 & 50 \\
2. & E. striatum & 5 & 3 & 40 \\
\hline
\end{tabular}

Pelatihan yang dibarengi dengan demonstrasi teknik budidaya rumput laut sangat berperan penting terhadap peningkatan mutu hasil budidaya baik kualitas maupun kuantitasnya. Hal ini terlihat dari peningkatan berat basah maupun berat kering rumput laut E. cottonii dan E. striatum sebelum maupun setelah pelatihan. Peningkatan berat basah dan berat kering rumput laut dapat meningkatkan jumlah produksi dan harga jual dari komoditi tersebut. Penurunan kadar kotoran (Tabel 5) merupakan salah satu faktor penting dalam peningkatan mutu rumput laut, sehingga harga jual yang semula Rp. 14.000 per 
kilogram berat kering menjadi Rp. 22.000 per kilogram berat kering. Keberhasilan penigkatan hasil budidaya rumput laut tidak lepas dari minat masyarakat terhadap pelatihan dan demonstrasi yang dilakukan.

\section{Kesimpulan}

Pelatihan yang dibarengi dengan demonstrasi teknik budidaya rumput laut jenis E. cottonii dan E. striatum dapat meningkatkan berat basah, berat kering, persentase rendemen dan menurunkan kadar kotoran. Rumput laut yang dihasilkan memiliki mutu tinggi sehingga harga jual lebih tinggi, dengan harga sekitar 22.000 rupiah per kilogram berat kering.

\section{Ucapan Terimakasih}

Penulis mengucapkan terimakasih
kepada dewan DRIN riset dan inovasi
Kemenristek RI yang telah menyediakan
anggaran pengabdian masyarakat PPDM
tahun 2020, rektor Universitas Mataram dan
seluruh pihak yang telah berpartisipasi dan
berkontribusi selama kegiatan berlangsung,
terutama kelompok masyarakat pembudidaya
rumput laut di Teluk Ekas, Lombok Timur

\section{Daftar Pustaka}

Alamsyah, R., Lestari, M. dan Hasrini, R.F. (2013). Kajian Mutu Bahan Baku Rumput Laut (Eucheuma Sp.) dan Teknologi Pangan Olahannya. Jurnal Dinamika Penelitian Industri. 24(1): 57-67.

Ega, L., Lopulalan, C.G.C. dan Meiyasa F. 2016. Kajian Mutu Karaginan Rumput Laut Eucheuma cottonii Berdasarkan Sifat Fisika-Kimia pada Tingkat Konsentrasi Kalium Hidroksida $(\mathrm{KOH})$ yang Berbeda. Jurnal Aplikasi Teknologi Pangan. 5(2): 3844.
Herawati, H. 2018. Potensi Hidrokoloid Sebagai Bahan Tambahan Pada Produk Pangan Dan Nonpangan Bermutu. Jurnal Litbang Pertanian. 3(1): 17-25. doi: 10.21082/jp3.v37n1.2018.p17-25.

Sunarpi., Jupri, A., Gazali, M. Nikmatullah, A. 2005. Seaweed Cultivation in NTB. Proceeding on International Seaweed Forum. Clarion Hotel, Makassar. Indonesia.

Ortodo, E. 2005. Seaweed Cultivation in Philippine. Proceeding International Seaweed Forum. Clarion Hotel, Makassar. Indonesia. 